\title{
Protective Effects of Silymarin against Cardiac Tissue Injury Caused By a High-dose Administration of Isotretinoin in Mice
}

Meltem KUMAŞ', Mukaddes EŞREFOĞLU², Ömer Faruk ÖZER ${ }^{3}$

'Programme Medical Laboratory Techniques, Bezmialem University Vocational Health High School, İstanbul, Turkey

${ }^{2}$ Division of Basic Medical Sciences, Department of Histology and Embryology, Bezmialem Vakıf University School of Medicine, İstanbul,

Turkey

${ }^{3}$ Division of Basic Medical Sciences, Department of Medical Biochemistry, Bezmialem Vakıf University School of Medicine, İstanbul, Turkey

\section{ABSTRACT}

Objective: We aimed to histopathologically and biochemically investigate the protective effects of silymarin (SLY) against cardiac injury induced by a high-dose isotretinoin (ISR) administration.

Methods: Thirty-two male Balb/c mice were divided into four groups: control, ISR, SLY, and co-treated (ISR+SLY) groups. For the histopathological analysis, all sections were stained with hematoxylin-eosin and Masson's trichrome. The TUNEL detection kit was used for the detection of cardiac apoptosis. The oxidative stress markers, which included catalase (CAT), superoxide dismutase (SOD), glutathione (GSH), glutathione peroxidase (GSH-Px), and glutathione reductase (GSH-red), and the glutathione S-transferase (GST) and lipid peroxidation markers, which included erythrocyte malondialdehyde (E-MDA) and plasma malondialdehyde (P-MDA), were biochemically determined. All statistical analyses were conducted with SPSS 18.0 (IBM, New York, USA) and GraphPad Prism Version 6.01 (USA). The Student's t-test was applied to the parametric data for comprising among groups. The P-significance degree was evaluated as $95 \%$.

Results: Severe histopathological alterations were observed in cardiac tissue. The ISR group showed hemorrhage, necrosis, edema, and congestion in cardiac tissues. SLY did not improve ISR-induced histopathological changes ( $p>0.05$ ). The highest number of apoptotic cells was detected in the ISR group. In the ISR+SLY group, SLY treatment reduced apoptosis $(\mathrm{p} \leq 0.05)$. Antioxidant enzyme activities (CAT, SOD, GSH-Px, GSH-Red, GSH, GST) were induced in ISR+SLY group ( $\mathrm{p}=0.015, \mathrm{p}>0.05, \mathrm{p}=0.002, \mathrm{p}=0.002, \mathrm{p}=0,018$, $\mathrm{p}=0.002$; respectively). E-MDA $(\mathrm{p}=0.003)$ and $\mathrm{P}-\mathrm{MDA}(\mathrm{p}=0.005)$ levels significantly increased in the ISR group and decreased in the SLY group.

Conclusion: SLY increased antioxidant enzyme activities, prevented lipid peroxidation, and decreased apoptosis. SLY was found to be an antioxidant against ISR-induced cardiac oxidative damage.

Keywords: Isotretinoin, silymarin, heart, oxidative stress, apoptosis, histopathology

\section{Introduction}

Isotretinoin (ISR), which is also known as 13-cis-retinoic acid, is a vitamin A derivative that suppresses the proliferation of sebaceous glands, keratinization of hair follicles, and the activity of inflammatory cytokines (1-4). This substance is widely used in the treatment of acne vulgaris at present. However, its long-term use often causes disorders in the liver and kidney tissues. In addition to its toxic effects, it is a powerful teratogenic agent (5). It has also been shown to cause depression by lowering orbitofrontal cortex activity in patients (3).

Retinoic acid, synthesized from the epicardium during embryonic development, is required for the development of cardiac myocytes (6). Secretion of retinoic acid that is less or more than normal has been demonstrated to cause abnormal heart development and heart defects during this period (7). However, no studies showing that high-dose retinoic acid intake creates a pathological or toxic effect on heart tissue have been encountered. 
Silymarin (SLY) is among the flavonolignans that are condensed in the seed extracts of the Silybum marianum plant (8). SLY, which is a powerful antioxidant, has been shown to inhibit lipid peroxidation and prevent oxidative damage by increasing the levels or activity of antioxidant enzymes, especially glutathione (GSH) (9-13). It has been reported that SLY, which was shown in various studies to have protective effects, especially on the heart, kidney, and the organs of the nervous system, reduces the activity of carcinogens and regulates immunological functions $(14,15)$.

In this study, we aimed to determine the histopathological and biochemical changes that high-dose ISR applied to BALB/c mice would create in the heart tissue, and to determine the possible antioxidative effects of SLY on these changes. To the best of our knowledge, this is the first study conducted on this subject.

\section{Methods}

\section{Experimental plan}

In our study, $32 \mathrm{BALB} / \mathrm{c}$ young (3 months) male mice were used. During the 6-week experiment, all mice were fed with normal pelleted feed and tap water. Randomly selected mice were divided into control, ISR, SLY, and ISR+SLY groups, with 8 mice in each. ISR was bought from the Alfa Aesar (J61666, Massachusetts, USA) company and SLY (S0292) from Sigma-Aldrich, (Germany).

Dimethyl sulfoxide (DMSO)+physiological saline solution ((PSS), which is the solvent for ISR and SLY) was applied to the control groups at a ratio of 1:1 during the experiment. ISR was dissolved in $0.1 \mathrm{~mL}$ of DMSO+PSS and was given at a dose of $40 \mathrm{mg} / \mathrm{kg} /$ day for 6 weeks through oral gavage, and SLY was dissolved in $0.2 \mathrm{~mL}$ of DMS+PSS and was given at a dose of $200 \mathrm{mg} / \mathrm{kg} / \mathrm{day}$ in the same way. In order to determine the possible therapeutic effect of silymarin, ISR was initially administered to the ISR+SLY group, and after 4 hours, SLY was administered at the indicated doses. At the end of the experiment, cardiac blood samples were taken for biochemical analysis under anesthesia administered intraperitoneally with $5 \mathrm{mg} / \mathrm{kg}$ xylazine and $80 \mathrm{mg} / \mathrm{kg}$ ketamine. Following this procedure, the hearts were removed and procedures were started for histopathological evaluation.

The study methods were approved by decision No. 2013-237 of the Experimental Animals Local Ethics Committee of the Bezmiâlem Foundation University.

\section{Histological procedures}

The removed cardiac tissues were divided in two and fixed in $10 \%$ neutral buffered formaldehyde for 1 week. Then, they were dehydrated by being passed through an alcohol series whose densities progressively increased. Sections that were $4-\mu \mathrm{m}$ thick were taken from blocks obtained by paraffin embedding and stained with hematoxylin-eosin and Masson trichrome. Samples were examined with a light microscope
Tokyo, Japan) and the changes were scored (Nikon NIS Elements version 4.0 imaging analysis system; Nikon Instruments Inc., Tokyo, Japan).

Scoring was histopathologically performed considering necrosis, bleeding, and intercellular edema. Evaluation was made for each datum as 0 : No change; 1 : slight change; 2 : moderate change; 3 : severe change. The total maximum mean histopathological score (MHS) values for each sample were evaluated as 9 .

The TUNEL (terminal deoxynucleotidyl transferase-mediated dUTP-X nick end labeling assay, Roche-11 684795 910-kit) fluorescence staining technique was used to identify apoptotic cells. The staining method was carried out as specified by the manufacturer. The number of apoptotic cells was obtained by counting the TUNEL-positive cells and calculating the group averages in 20 sites randomly selected at $20 \times$ magnification in each section under a fluorescence microscope.

\section{Biochemical procedures}

\section{Sample collection and preparation}

Blood samples were collected by cardiac puncture into heparinized tubes. After removing the plasma parts of samples by centrifuging at $1,500 \mathrm{xg}$ for 10 minutes, the remaining erythrocyte suspension was washed three times with $0.9 \%$ cold sodium chloride $(\mathrm{NaCl})$ at equal volumes. Samples were stored at $-20^{\circ} \mathrm{C}$ until the parameters were analyzed.

\section{Measurement of hemoglobin $(\mathrm{Hb})$}

The erythrocyte concentration in the hemolysates was spectrophotometrically measured using the cyanmethemoglobin method (16). Blood samples were mixed with $5 \mathrm{ml}$ Drabkin's solution ( $1 \%$ sodium bicarbonate, $0.005 \%$ potassium cyanide, and $0.02 \%$ potassium ferricyanide) for determining $\mathrm{Hb}$ concentrations. An $\mathrm{Hb}$ standard was obtained from Sigma (St. Louis, MO, USA).

\section{Antioxidant enzyme measurements}

Superoxide dismutase (SOD) activity in erythrocyte hemolysates was measured by the reduction inhibition rate of 2-(4-iodophenyl)-3-(4-nitrophenyl)-5-phenyl tetrazolium chloride (INT) (Ransod SD 125, Randox Lab.) and Hb was specified as $\mathrm{U} / \mathrm{g}$.

GSH peroxidase (GSH-Px) activity in full blood was measured using the modified method described by Paglia and Valentine (17). GSH-Px catalyzes the GSH oxidation with hydroperoxide clusters. In the presence of GSH reductase and $\mathrm{NADPH}$, oxidative GSH (GSHG) is rapidly converted to a reduced form, resulting from the oxidation of NADPH to NADP. The decrease in absorbance was measured at a wavelength of $340 \mathrm{~nm}$ (Ransel RS 505, Randox Lab.). The activity of GSH reductase was measured spectrophotometrically at a wavelength of $340 \mathrm{~nm}$ (18). GSH peroxidase catalyzes the oxidation of GSH to GSSG by means of hydrogen peroxide. The conversion rate of GSSG is measured by the GSH re- 
ductase reaction (19). GSH transferase (GST) activity was assessed using the method specified by Habig et al. (20). The reduced GSH level in erythrocyte hemolysates was determined by Beutler's method (21).

Catalase (CAT) was spectrophotometrically measured at 230 $\mathrm{nm}$ by a procedure based on the measurement of the oxygen volume that occurs as a result of the dissociation of hydrogen peroxide. SOD, CAT, and GSH-Px activities were expressed as $\mathrm{Hb} \mathrm{U} / \mathrm{g}$. All antioxidant enzyme activities were measured on a multi-plate reader (Varioskan Flash Multimode Reader, Thermo, USA).

\section{Lipid peroxidation}

Lipid peroxidation was measured in red blood cells by using the method stated by Stocks et al. (22), and in plasma samples by using the method stated by Ohkawa et al. (23). Other aldehydes were calculated by monitoring the pink color resulting from the reaction between MDA and thiobarbituric acid.

\section{Statistical analysis}

For comparing histopathological changes and the number of apoptotic cells among the groups, a t-test was used. The significance level was considered as $\mathrm{p} \leq 0.05$. All statistical analyses were performed by using Statistical Package for the Social Sciences 18.00 (SPSS, IBM Corp., New York, USA) software. Bar graphs were prepared through GraphPad Prism Version 6.01 (USA) software.

\section{Results}

\section{Biochemical analyses}

The levels of GSH ( $\mathrm{p}=0.013)$, GSH-Red ( $\mathrm{p}=0.002)$, and GST $(\mathrm{p}=0.002)$, and the activities of GSH-Px $(\mathrm{p}=0.002)$, CAT $(\mathrm{p}=0.002)$, and SOD $(\mathrm{p}=0.003)$ in the group of isotretinoin were seen to be quite low compared to the control group. The highest antioxidant enzyme levels were detected in the SLY group. After the application of ISR, SLY application was determined to have significantly increased the antioxidant enzyme level [GSH ( $\mathrm{p}=0.018)$, GSH-Px $(\mathrm{p}=0.002), \mathrm{GSH}-\mathrm{Red}$ $(\mathrm{p}=0.002)$, GST $(\mathrm{p}=0.002)$, CAT $(\mathrm{p}=0.015), \operatorname{SOD}(\mathrm{p}>0.05)]$.

The mean E-MDA ( $\mathrm{p}=0.004)$ and P-MDA $(\mathrm{p}=0.004)$ values for the isotretinoin group were higher than for the control group. It was observed that SLY application significantly reduced E-MDA ( $\mathrm{p}=0.003)$ and P-MDA ( $\mathrm{p}=0.005)$ values and, consequently, the lipid peroxidation.

All biochemical results are shown in Table 1 and in Figures 1 and 2.

\section{Histopathological analyses}

In the control group, it was seen that all the layers of the heart were of normal histological appearance, and that the heart muscle cells preserved their normal cellular properties. No pathological findings were discovered in this group (Figure $3 a, b)$. In the SLY group, all the layers were also of normal appearance in general. The microscopic characteristics of the

\begin{tabular}{|c|c|c|c|c|}
\hline & Group & MeanıSD & Minimum & Maximum \\
\hline \multirow[t]{4}{*}{ CAT } & Control & $289.14 \pm 63.11$ & 212.00 & 374.00 \\
\hline & ISR & $644.14 \pm 128.06$ & 420.00 & 780.00 \\
\hline & SLY & $1234.71 \pm 171.09$ & 985.00 & 1462.00 \\
\hline & ISR+SLY & $821.14 \pm 90.77$ & 708.00 & 956.00 \\
\hline \multirow[t]{4}{*}{ SOD } & Control & $1229.00 \pm 166.03$ & 1004.00 & 1535.00 \\
\hline & ISR & $1693.29 \pm 148.02$ & 1480.00 & 1909.00 \\
\hline & SLY & $2073.00 \pm 173.82$ & 1854.00 & 2401.00 \\
\hline & ISR+SLY & $1761.57 \pm 183.63$ & 1449.00 & 2017.00 \\
\hline \multirow[t]{4}{*}{ E-MDA } & Control & $305.87 \pm 54.17$ & 208.40 & 381.20 \\
\hline & ISR & $424.90 \pm 42.47$ & 384.79 & 485.69 \\
\hline & SLY & $235.40 \pm 27.88$ & 196.00 & 272.70 \\
\hline & ISR+SLY & $314.95 \pm 20.10$ & 285.63 & 345.62 \\
\hline \multirow[t]{4}{*}{ P-MDA } & Control & $0.66 \pm 0.12$ & 0.56 & 0.84 \\
\hline & ISR & $0.97 \pm 0.11$ & 0.78 & 1.10 \\
\hline & SLY & $0.24 \pm 0.04$ & 0.17 & 0.30 \\
\hline & ISR+SLY & $0.69 \pm 0.10$ & 0.58 & 0.84 \\
\hline \multirow[t]{4}{*}{ GSH } & Control & $4.62 \pm 0.17$ & 4.34 & 4.88 \\
\hline & ISR & $4.16 \pm 0.33$ & 3.74 & 4.78 \\
\hline & SLY & $5.78 \pm 0.33$ & 5.33 & 6.12 \\
\hline & ISR+SLY & $5.18 \pm 0.6$ & 4.10 & 6.01 \\
\hline \multirow[t]{4}{*}{ GSH-Red } & Control & $2.35 \pm 0.79$ & 1.70 & 4.08 \\
\hline & ISR & $4.60 \pm 0.35$ & 4.09 & 5.04 \\
\hline & SLY & $6.59 \pm 0.40$ & 5.92 & 7.03 \\
\hline & ISR+SLY & $5.79 \pm 0.36$ & 5.13 & 6.27 \\
\hline \multirow[t]{4}{*}{ GSH-PX } & Control & $36.18 \pm 6.01$ & 30.01 & 44.65 \\
\hline & ISR & $73.79 \pm 10.23$ & 58.65 & 89.65 \\
\hline & SLY & $113.02 \pm 12.49$ & 99.77 & 135.77 \\
\hline & ISR+SLY & $89.43 \pm 8.73$ & 74.63 & 98.74 \\
\hline \multirow[t]{4}{*}{ GST } & Control & $25.36 \pm 4.53$ & 18.96 & 31.47 \\
\hline & ISR & $54.40 \pm 5.10$ & 47.44 & 60.12 \\
\hline & SLY & $88.43 \pm 6.46$ & 82.11 & 99.16 \\
\hline & ISR+SLY & $73.36 \pm 4.31$ & 66.66 & 79.53 \\
\hline
\end{tabular}

CAT: catalase; SOD: superoxide dismutase; E-MDA: erythrocyte malondialdehyde; P-MDA: plasma malondialdehyde; GSH: glutathione; GSH-red: glutathione reductase; GSH-Px: glutathione peroxidase; GST: glutathione-Stransferase; SD: Standard deviation; ISR: isotretinoin group; SLY: silymarin group; ISR+SLY: isotretinoin and silymarin group

heart muscle cells were the same as in the control group (Figure 4). A very small amount of bleeding was observed between the muscle fibers only in one mouse.

Necrosis, hemorrhage, and intercellular edema were quite apparent in the heart tissues of the isotretinoin groups. The muscle fibers were observed to be quite distant from each other because of severe edema and hemorrhage (Figure 5a, b, 6). It was observed with the hematoxylin-eosin staining method 

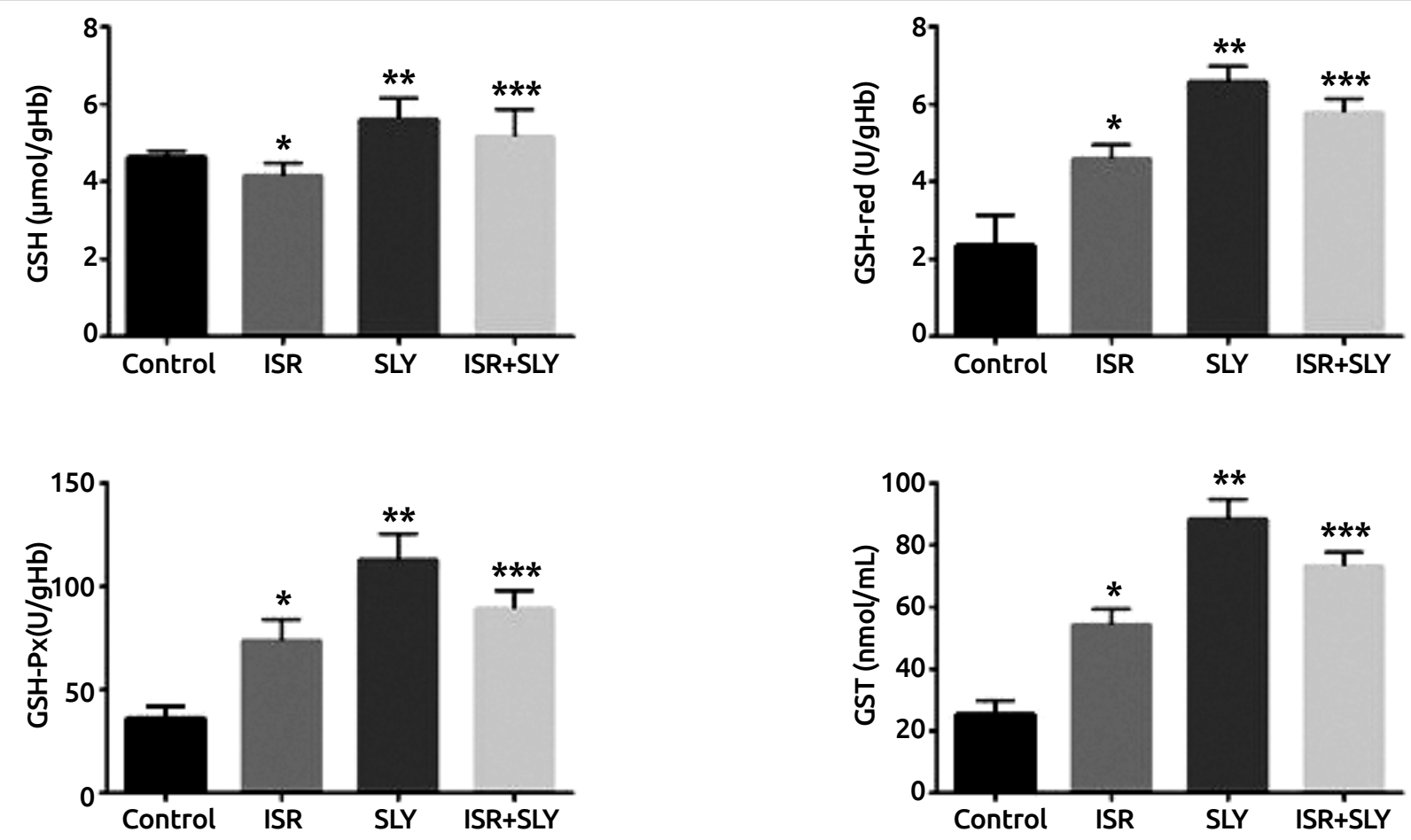

Figure 1. Bar graphs of mean GSH, GSH-Px, GSH-red, and GST levels *: ISR and SLY groups

**: This shows that the difference between ISR and ISR+SLY groups is significant $(p \leq 0.05)$.
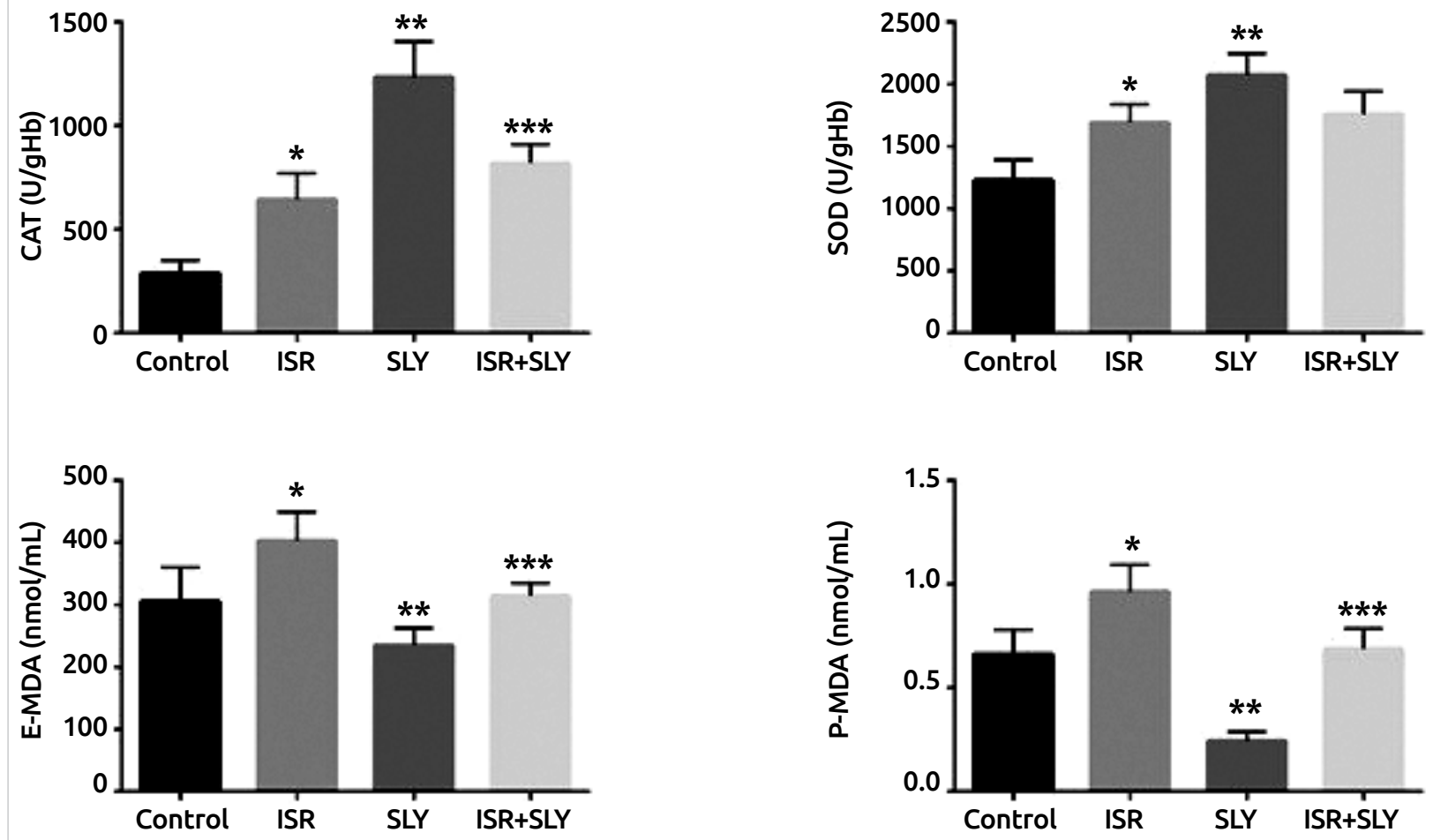

Figure 2. Bar graphs of mean CAT, SOD, E-MDA, and P-MDA levels

*: ISR and SLY groups;

**: This shows that the difference between ISR and ISR+SLY groups is significant $(p \leq 0.05)$.

that the cytoplasm of the necrotic cells was darker and more acidophilic than that of the healthy heart cells, and the nuclei tion was encountered sporadically, though not common in the sections (Figure 7). The MHS of this group was higher than that of the control group $(\mathrm{p}=0.001)$. 


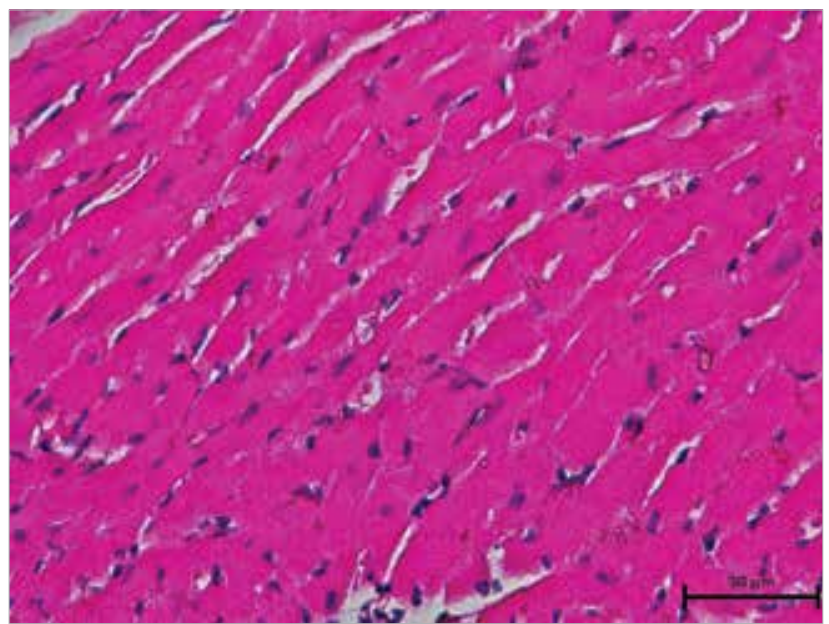

Figure 3. In the control group, heart tissues are of normal histological appearance (hematoxylin-eosin staining, 40x)

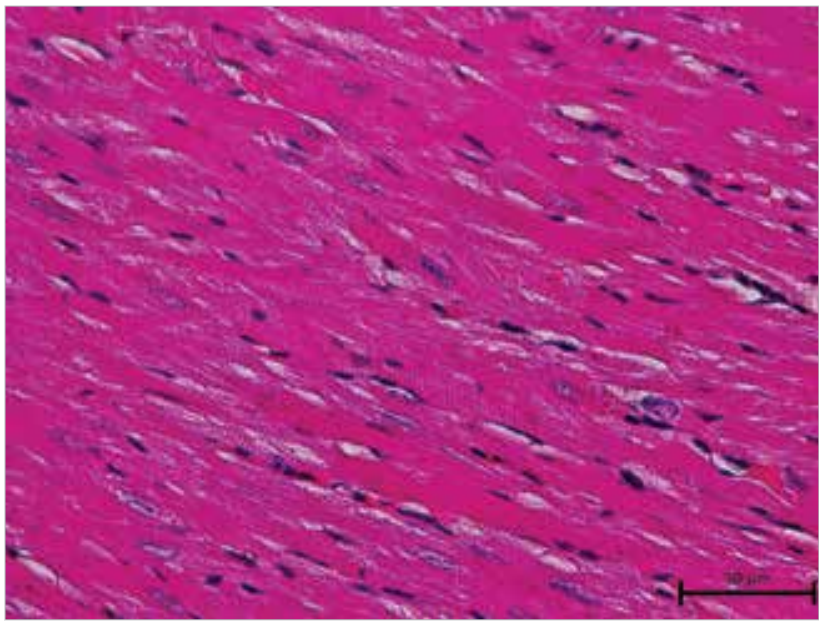

Figure 4. In the SLY group, the histological structure of the heart tissues has a normal appearance (hematoxylin-eosin staining, 40x)
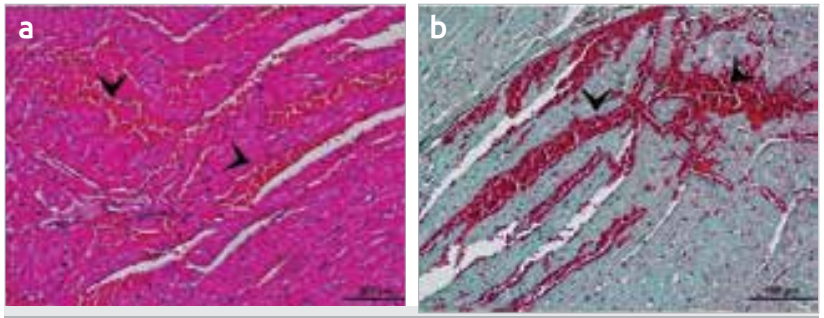

Figure 5. In the ISR group, intense bleeding areas are shown with arrowheads. (a) hematoxylin-eosin staining (b) Masson's trichrome staining, 20x

In the ISR+SLY group, which was designed as a treatment group, it was observed that the findings obtained were not different from the ISR group; similar to this group, the areas of hemorrhage and necrosis covered a large area and the muscle fibers were separated from each other (Figure 8). The mean histopathological scores were found to be almost the same in both groups (Table 2). Although there were no dif-

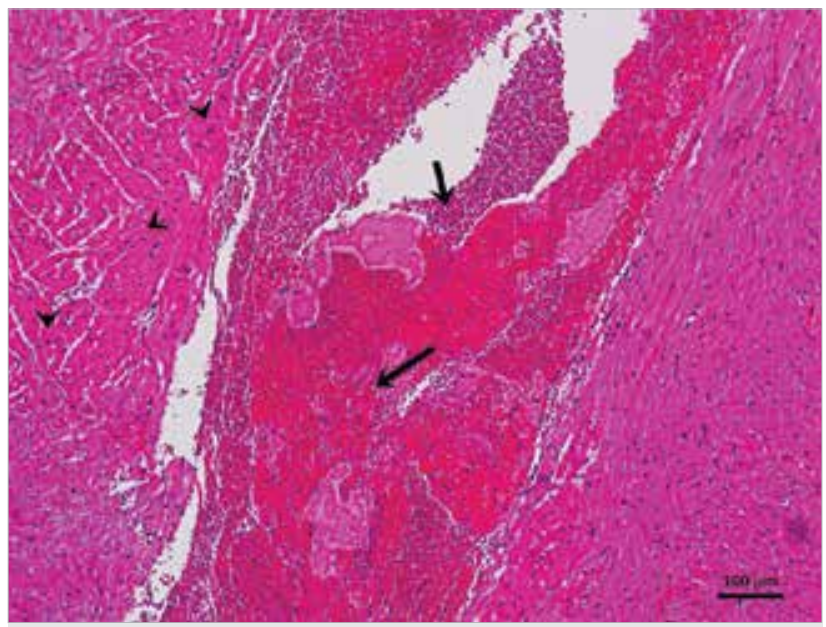

Figure 6. In the ISR group, bleeding and edematous areas (arrows) and necrotic areas are viewed (arrowheads) (hematoxylin-eosin staining, 10x)

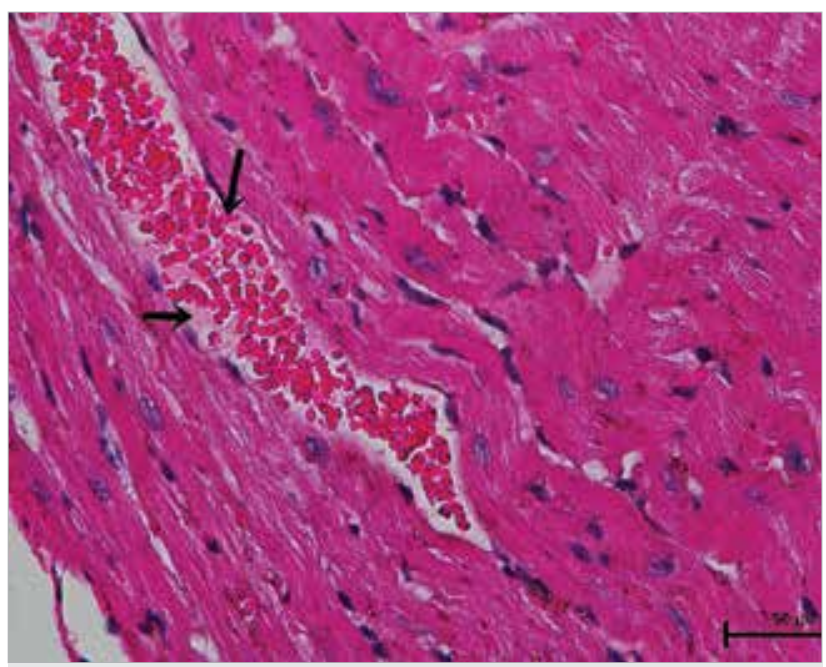

Figure 7. In the ISR group, congestion is seen (arrows) (hematoxylin-eosin staining, 40x)

ferences in the ISR and ISR+SLY groups in terms of general scoring results, a statistically significant difference was found between the two groups in terms of necrosis density $(\mathrm{p} \leq 0.001)$ (Table 3).

The mean number of apoptotic cells determined by the TUNEL method was $14.25 \pm 6.36$ in the control group, $13.00 \pm 5.37$ in the SLY group, $57.88 \pm 38.26$ in the ISR group, and $20.75 \pm 7.15$ in the ISR+SLY group (Table 4 ). It was observed that ISR induced apoptosis and SLY suppressed apoptosis alone or after ISR application $(\mathrm{p}=0.017)$ (Figure 9, 10).

\section{Discussion}

It was shown that ISR induced cardiac remodeling (24) in rats in which ISR was applied at normal physiological doses $(0.5 \mathrm{mg} / \mathrm{kg})$ and prevented fibrosis and hypertrophy of the heart in patients who received acne vulgaris treatment (25). 


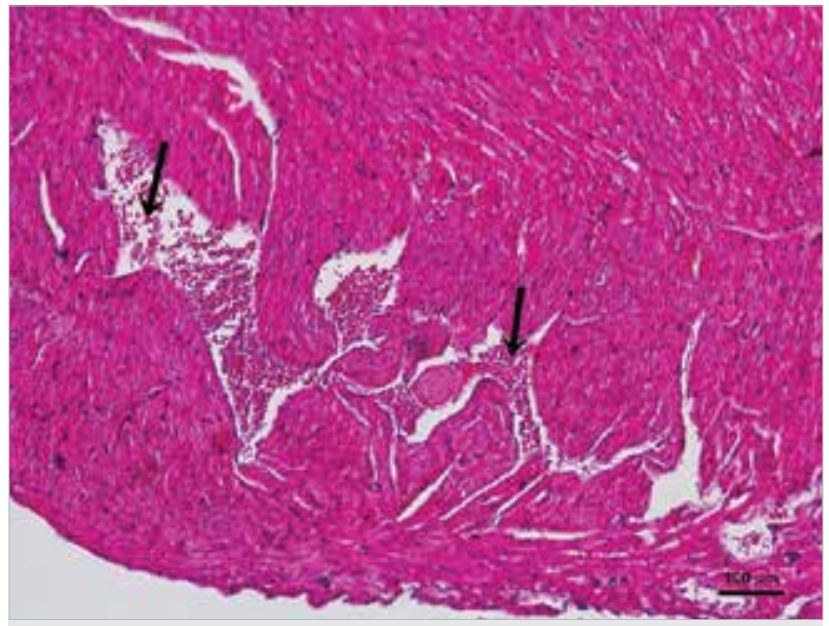

Figure 8. In the ISR+SLY group, bleeding and edematous areas are seen (arrows) (hematoxylin-eosin staining, 10x)

Tablo 2. Brief statistical data on histopathological scoring

\begin{tabular}{|l|c|c|c|}
\hline Group & Mean \pm SD & Minimum & Maximum \\
\hline Control & $1.25 \pm 0.46$ & 1.00 & 2.00 \\
\hline ISR & $5.25 \pm 1.28$ & 3.00 & 7.00 \\
\hline SLY & $2.13 \pm 1.13$ & 1.00 & 4.00 \\
\hline ISR+SLY & $5.63 \pm 1.60$ & 3.00 & 7.00 \\
\hline
\end{tabular}

SD: standard deviation; ISR: isotretinoin group; SLY: silymarin group; ISR+SLY: isotretinoin and silymarin group

Tablo 3. Brief statistical data on necrotic area

\begin{tabular}{|l|c|c|c|}
\hline Group & Mean \pm SD & Minimum & Maximum \\
\hline Control & 0 & 0 & 0 \\
\hline ISR & $983.4 \pm 421.9$ & 375.2 & 2489.5 \\
SLY & 0 & 0 & 0 \\
\hline ISR+SLY & $370.9 \pm 145.7$ & 326.9 & 768.9 \\
\hline
\end{tabular}

SD: standard deviation; ISR: isotretinoin group; SLY: silymarin group; ISR+SLY: isotretinoin and silymarin group

It was observed in our study that long-term administration of high-dose ISR caused severe necrosis, interstitial edema, congestion, and bleeding in the heart. As a matter of fact, the MHS, e-MDA, and $\mathrm{p}-\mathrm{MDA}$ values of this group were higher than for the control group $(\mathrm{p}=0.001, \mathrm{p}=0.004$, and $\mathrm{p}=0.004$, respectively). MDA is the end product of lipid peroxidation and is one of the most important indicators of the cell membrane integrity, and thus cell damage. Indeed, we have shown that ISR administration also causes apoptotic and necrotic cell death in the liver and kidney tissues (unpublished finding). On the other hand, in our study, significant decreases in antioxidant enzyme levels or activities in the ISR group indicate that ISR suppresses cellular antioxidant enzyme systems.

\section{Tablo 4. Brief statistical data on apoptotic cell number}

\begin{tabular}{|l|c|c|c|}
\hline Group & Mean \pm SD & Minimum & Maximum \\
\hline Control & $14.25 \pm 6.36$ & 5.00 & 24.00 \\
\hline ISR & $57.88 \pm 38.26$ & 26.00 & 148.00 \\
\hline SLY & $13.00 \pm 5.37$ & 7.00 & 21.00 \\
\hline ISR+SLY & $20.75 \pm 7.15$ & 11.00 & 35.00 \\
\hline
\end{tabular}

SD: standard deviation; ISR: isotretinoin group; SLY: silymarin group; ISR+SLY: isotretinoin and silymarin group

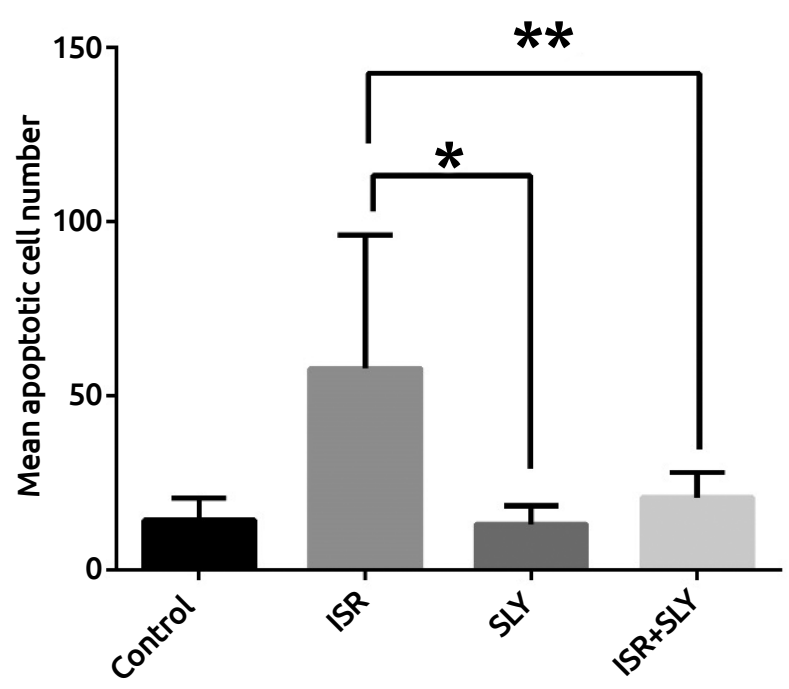

Figure 9. Bar graph showing the mean apoptotic cell number

*: ISR and SLY groups

$* *$ : This shows that the difference between the ISR and ISR+SLY groups is significant $(p \leq 0.05)$.

It has been shown that silymarin inhibits the entry of toxic agents into cells by increasing cell membrane resistance. In our study, it was important that SLY was given approximately simultaneously with ISR in order to prevent toxic effects. In many studies, SLY has been shown to prevent lipid peroxidation and to have antioxidant effects by increasing GSH levels and CAT enzyme activities (9-13, 15). As in previous studies, we found that SLY increased antioxidant enzyme levels and prevented lipid peroxidation. As a matter of fact, all antioxidant levels of the ISR+SLY group were significantly higher than in the ISR group. Conversely, necrosis rates, e-MDA, and p-MDA levels were significantly lower $(\mathrm{p} \leq 0.001, \mathrm{p}=0.003$, and $\mathrm{p}=0.005$, respectively). Moreover, the rate of apoptosis, which was quite high in the ISR group, was observed to decrease significantly with SLY administration ( $\mathrm{p}=0.017)$. SLY has been shown to protect cells against DNA damage, with antiapoptotic properties in addition to antioxidant effects (26). These data demonstrate that SLY suppresses cellular damage by supporting the antioxidant enzyme system. It was reported in a similar study that SLY showed a protective effect against doxorubicin-induced mild cardiac damage (15). One notable result of our study 


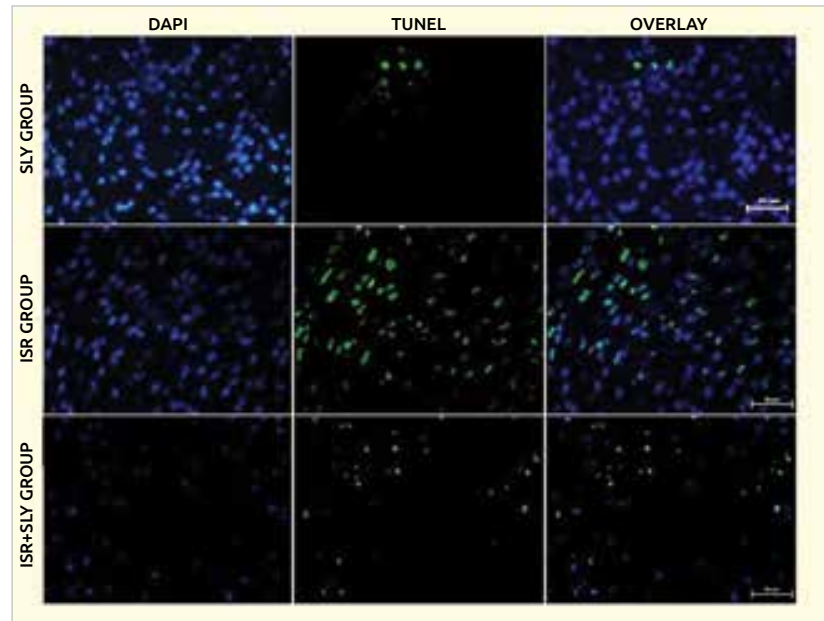

Figure 10. The view of apoptotic cells under fluorescence microscope with TUNEL staining (All nuclei were stained blue with DAPI, and positive apoptotic cell nuclei were stained green with TUNEL, $40 x)$

was that SLY did not suppress intercellular edema, congestion, and bleeding. No study suggesting that SLY is effective against edema, bleeding, and congestion has been encountered so far. The prevention of cellular damage is a very promising finding for the treatment of various conditions where cardiac tissue with poor regeneration power becomes damaged. However, in order to make the results more meaningful, it could be suggested that the study should be renewed by making lipid peroxidation and antioxidant agent measurements of the heart tissue.

\section{Conclusion}

In the result of the evaluations; it was observed that silymarin increased the activities of antioxidant enzymes, primarily plasma GSH enzyme levels, and reduced lipid peroxidation by lowering the E-MDA and P-MDA levels, against heart tissue damage caused by high-dose isotretinoin. In addition, it was specified to have apoptosis-lowering effect by partially suppressing apoptotic cell death caused by isotretinoin. As a result, it was concluded that silymarin has an antioxidant and antiapoptotic effect on heart tissue.

Ethics Committee Approval: Ethics committee approval was received for this study from Bezmiâlem Vakıf University Ethics Committee of Experimantal Animal.

\section{Informed Consent: N/A}

Peer-review: Externally peer-reviewed.

Author Contributions: Concept - M.K., M.E.; Design - M.K., M.E.; Supervision - M.K., M.E., Ö.F.Ö.; Funding - M.K., M.E., Ö.F.Ö.; Materials - M.K., M.E., Ö.F.Ö.; Data Collection and/or Processing - M.K., M.E.; Analysis and/or Interpretation - M.K., M.E., Ö.F.Ö.; Literature Review M.K.; Writing - M.K., M.E.; Critical Review - M.E.

Conflict of Interest: No conflict of interest was declared by the authors.
Financial Disclosure: This was supported by the Research Fund Accountancy of Bezmialem Vakif University, Istanbul/Turkey (Project number:12.2013/9).

\section{References}

1. Cunliffe WJ, van der Kerkhof PCM, Caputo R, Caicchini S, Cooper A, Fyrand OL, Gollnick H, et al. Roaccutane treatment guidelines: results of an international survey. Dermatology 1997; 194: 351-7. [CrossRef]

2. Goulden V, Layton AM, Cunliffe WJ. Current indications for isotretinoin as a treatment for acne vulgaris. Dermatology 1995; 190: 284-7. [CrossRef]

3. Bremner JD, Fani N, Ashraf A, Votaw JR, Brummer ME, Cummins T, et al. Functional brain imaging alterations in acne patients treated with isotretinoin. Am J Psychiatry 2005; 162: 983-91. [CrossRef]

4. Dispenza MC, Wolpert EB, Gilliland KL, Dai JP, Cong Z, Nelson AM, et al. Systemic isotretinoin therapy normalizes exaggerated TLR-2mediated innate immune responses in acne patients. J Invest Dermatol 2012; 132: 2198-205. [CrossRef]

5. Blommhorf, R. 1994. Vitamin A in health and disease, p.344.

6. Stuckmann I, Evans S, Lassr AB. Erythropoietin and retinoic acid, secreted from the epicardium, are required for cardiac myocyte proliferation. Developmental Biology 2003; 255: 334-349. [CrossRef]

7. Sinning AR. Role of vitamin A in the formation of congenital heart defects. Anat Rec 1998; 253: 147-53. [CrossRef]

8. Tedesco D, Tava A, Galletti S, Tameni M, Varisco G, Costa A, et al. Effects of silymarin, a natural hepatoprotector, in periparturient dairy cows. Journal of Dairy Science 2004; 87: 2239-47. [CrossRef]

9. Mira L, Silva M, Manso CF. Scavenging of reactive oxygen species by silibinin dihemisuccinate. Biochemical Pharmacology 1994; 48: 753-9 [CrossRef]

10. Lettéron P, Labbe G, Degott C, Berson A, Fromenty B, Delaforge M, et al. Mechanism for the protective effects of silymarin against carbon tetrachloride-induced lipid peroxidation and hepatotoxicity in mice. Biochemical Pharmacology 1990; 39: 2027-34. [CrossRef]

11. Wellington, K. and Harvis, B. Silymarin. A review of its clinical properties in the management of hepatic disorders. Biodrugs 2001; 15: 465-89. [CrossRef]

12. Soto C, Recoba R, Barron H, Alvarez C, Favori L. Silymarin increases antioxidant enzymes in alloxan induced diabetes in rat pancreas. Comparative Biochemistry and Physiology Part C. Toxicology and Pharmacology 2003; 136: 205-12. [CrossRef]

13. Soto C, Perez J, Garcia V, Uria E., Vadillo, M., Raya L. 2010. Effect of silymarin on kidneys of rats suffering from alloxan induced diabetes mellitus. Phytomedicine 17: 1090-4. [CrossRef]

14. Zi X, Feyes DK, Agarwal R. Anticarcinogenic effect of a flavonoid antioxidant, silymarin. In human breast cancer cells MDA-MB 468: induction of G1 arrest through an increase in Cip1/p21 concomitant with a decrease in kinase activity of cyclin-dependent kinases and assosiated cyclins. Clinical Cancer Research 1998; 4: 1055-64.

15. Raskovic A, Stilinovic N, Kolarovic J, Vasovic V, Vukmirovic S, Mikov M. The protective effects of silymarin against doxorubicin-induced cardiotoxicity and hepatotoxicity in rats. Molecules 2011; 16: 8601-13. [CrossRef]

16. Drabkin DL. The standardization of hemoglobin measurement. American Journal of Medical Science 1949; 217: 710.

17. Paglia DE, Valentine WN. Studies on the quantitative and qualitative characterization of erythrocyte glutathione peroxidase. J Lab Clin Med 1967; 70: 158-69.

18. Beutler E. Effect of flavin compounds on glutathione reductase activity in vivo and in vitro studies. Journal of Clinical Investigation 1969; 48: 1957-1966. [CrossRef]

19. Beutler E, (editor). Glutathione peroxidase, Red Cell Metabolism. A manual of biochemical methods. 2nd ed. New York: Grune and Stratton, 1975; 71-3.

20. Habig WH, Pabst MJ, Jakoby WB. Glutathione S-transferases. The first enzymatic step in mercapturic acid formation. J Biol Chem 1974; 249: 7130-9. 
21. Beutler E, Duron O, Kelly BM. Improved method for the determination of blood glutathione. J Lab Clin Med 1963; 61: 882-8.

22. Stocks J, Offerman EL, Modell CB, Dormandy TL. The susceptibility to autoxidation of human red cell lipids in health and disease. British Journal of Hematology 1972; 23: 713-24. [CrossRef]

23. Ohkawa H, Ohishi N, Yagi K. Assay for lipid peroxides in animal tissues by thiobarbituric acid reaction. Anal Biochem 1979; 95: 351-8. [CrossRef]

24. Lu L, Yao T, Zhu YZ, Huang GY, Cao YX, Zhu YC. Chronic all-trans retinoic acid treatment prevents medial thickening of intramiyocardial and intrarenal arteries in spontaneously hypertensive rats. American
Journal of Physiology: Heart and Circulatory Physiology 2003; 285: 1370-7. [CrossRef]

25. Soriano EA, Azevedo PS, Miot HA, Minicucci MF, Pansani MC, Matsubara LS, et al. Cardiac remodeling induced by 13 -cis retinoic acid treatment in acne patients. Int J Cardiol 2013; 163: 68-71. [CrossRef]

26. Al-Rasheed NM, Al-Rasheed NM, Faddah LM, Mohamed AM, Mohammad RA, Al-Amin M. Potantial impact of silymarin in combination with chlorogenic acid and/or melatonin in combating cardiomyopathy induced by carbon tetrachloride. Saudi J Biol Sci 2014; 21: 265-74. [CrossRef] 